\title{
Closed Fracture of Rib
}

National Cancer Institute

\section{Source}

National Cancer Institute. Closed Fracture of Rib. NCI Thesaurus. Code C35350.

A traumatic break in one of the bones in the rib cage that does not involve a break in the adjacent skin. 